\title{
Design and Characterization of Alicyclic Polymers with Alkoxy-ethyl Protecting Groups for ArF Chemically Amplified Resists
}

\author{
Shigeyuki Iwasa, Katsumi Maeda, Kaichiro Nakano, \\ Takeshi Ohfuji, and Etsuo Hasegawa \\ Functional Devices Research Laboratories, NEC Corporation \\ 1-1, Miyazaki 4-chome, Miyamae, Kawasaki, Kanagawa, 216 Japan
}

We have developed new alkoxy-ethyl protecting groups for ArF chemically amplified positive resists. The developed groups show excellent performances in thermal stability, deprotection reaction efficiency, and dissolution contrast. Moreover, we find that the dissolution rates of polymers protected with these groups can be characterized by the polarity and molecular volume of the groups. ArF contact printing experiments also confirm that chemically amplified resists with these groups have good resolution capabilities. Thus the new alkoxy-ethyl groups are shown to have excellent performances as protecting groups for ArF chemically amplified resists.

\section{Introduction}

ArF excimer laser $(\lambda=193 \mathrm{~nm})$ lithography is a promising technology for manufacturing 1Gbit DRAMs $(<0.2 \mu \mathrm{m}$ design rule). However, conventional resist materials like novolac or poly(p-vinylphenol) can not be applied for resist material because of their strong absorption at $\mathrm{ArF}$ wavelength. Therefore, the use of alicyclic polymers with the tricyclodecanyl group ${ }^{1,2,3}$, adamantyl group ${ }^{4,5}$ and isobornyl group ${ }^{6,7}$ has been proposed for ArF lithography. For chemically amplified resists, however, these polymers have to be partially protected. The tetrahydropyranyl(THP) group ${ }^{1,2,3}$ and tert-Butyl(t-Bu) group ${ }^{3,4,6,7}$ have been widely used as protecting groups, although there are drawbacks to both. Polymers protected with the $\mathrm{t}-\mathrm{Bu}$ group have high thermal stability but low acid decomposition efficiency. On the other hand, THP group protected polymers have high acid decomposition efficiency but low thermal stability, and in addition have a side reaction problem. ${ }^{8,9}$ To solve the problem, we developed new alkoxy-ethyl protecting groups to obtain both good sensitivity and high thermal stability. This paper describes the basic characteristics of the developed alkoxy-ethyl groups and their application to ArF chemically amplified positive resist. 


\section{Experimental}

\subsection{Material}

\section{polymers}

The base polymers used in our experiments were terpolymer poly(TCDA-RMA-MAA) (Fig.1-(a)) and copolymer Poly(TCDMACOOR-TCDMACOOH)(Fig.1-(b)). These polymers were synthesized as described in the literature. ${ }^{2,3}$

\section{Protecting groups}

The protecting group structural formulas are shown in Fig. 2. The newly-developed alkoxy-ethyl protecting groups $\left(\mathrm{CH}_{3} \mathrm{CH}-\mathrm{O}-\mathrm{R}\right)$ were the ethoxy-ethyl (ETE) group, methoxyethoxy-ethyl (MEE) group, acetoxyethoxy-ethyl (AEE) group, adamantyloxyethoxyethyl (AdEE) group and admantylcarbonyloxyethoxy-ethyl (AdCEE) group. The ETE group has an ethyl ether structure, the MEE group was made by introducing the ether group into the ETE group, and the AEE group was made by introducing the ester group into the ETE group. The AdEE group has a structure in which the methyl group is changed to the adamantyl group in the MEE group, and the AdCEE group has a structure in which the methyl group is changed to the adamantyl group in the AEE group. Consequently, the AdEE and AdCEE protection groups improve dry etching resistance of resists, since the adamantyl group has high carbon density. ${ }^{4,5,10}$ The THP protection group was also used as a reference.

\section{Photoacid generators(PAGs)}

Triphenylsulfonium triflate(TPS) (Midori kagaku Co.) and hydroxysuccinimide tosylate (SIT) (Fig. 3) were used as photoacid generators. SIT was synthesized as described in the literature. $^{11}$<smiles>[R]OC(=O)C(C)(CC(C)(C)CCC(=O)OC1CC2CCC1CC2)C(=O)OCC(C)(C)C(=O)O</smiles>

(a)Poly(TCDA-RMA-MAA)

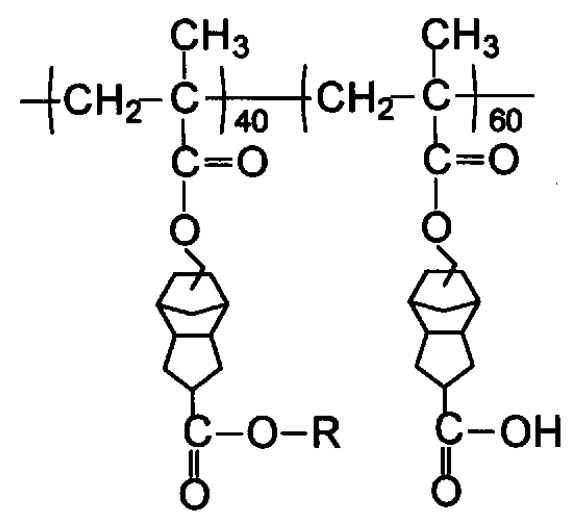

(b)Poly(TCDMACOOR-TCDMACOOH)

Figure 1. Chemical structures of polymers ( $R=$ protecting group) 
<smiles>CCOC(C)I</smiles>

ETE<smiles>COC(C)OC</smiles>

MEE<smiles>C=C(C)[C@H](OC(C)=O)OC(C)C</smiles><smiles>CC(I)OCCOC1C2C=CC1C2</smiles>

AdEE<smiles>COC(OCCOC(C)C)C1C2C=CC(C2)C1OC</smiles>

AdCEE<smiles>F[IH]C1CCCCC1</smiles>

THP

Figure 2. Chemical structures of alkoxy-ethyl protecting groups and THP group<smiles>C[As](O)(c1ccccc1)=S(c1ccccc1)c1ccccc1</smiles>

TPS<smiles>Cc1ccc(OS(=O)(=O)N2C(=O)CCC2=O)cc1</smiles>

SIT

Figure 3. Chemical structures of photoacid generators (PAGs)

\subsection{Measurements}

Dissolution rates of resist films were measured with an in-house dissolution rate monitor. ${ }^{12}$ Resists were prepared by dissolving the polymer and PAG $1 \mathrm{wt} \%$ in diethylene glycol dimethyl ether or propylene glycol monomethyl ether acetate and were filtered through a $0.2 \mu \mathrm{m}$ filter. Resist films were spun to $0.5 \mu \mathrm{m}$ thickness on a Si substrate and baked at $80^{\circ} \mathrm{C}$ for 60 seconds. $0.048 \mathrm{wt} \%$ tetramethylammonium hydroxide (TMAH) aqueous solution was used as a developer. Thermal stability was analyzed with a Mac Science System 001(TGA-DTA2000). FT-IR spectra were measured with Bio-Rad FTS155 using polymer films on Si substrate. ${ }^{13} \mathrm{C}-\mathrm{NMR}$ spectra were obtained using a Brukar Instrument AMX 400(400 MHz) .

\subsection{Lithography process conditions}

Process conditions are listed in Table 1. Exposure was carried out using an in-house ArF contact printing exposure tool. Wafers were baked at a temperature suitable for the protecting groups and then developed in TMAH solution. 
Table 1. Process conditions

\begin{tabular}{|c|l|}
\hline Process & \multicolumn{1}{|c|}{ Conditions } \\
\hline PAG Content & $1 \mathrm{wt} \%$ \\
Resist thickness & $0.5 \mu \mathrm{m}$ \\
Pre-Baking & $80^{\circ} \mathrm{C} / 60 \mathrm{~s}$ \\
Exposure & Contact printing exposure tool \\
PEB & $60,70,100^{\circ} \mathrm{C} / 60 \mathrm{~s}$ \\
Development & TMAH 0.0476 wt\% aqueous solution \\
\hline
\end{tabular}

\section{Results and Discussion}

\subsection{Thermal Stability}

Figure 4 shows a TGA thermogram of the terpolymers protected with alkoxy-ethyl groups and the THP group. The thermal decomposition points of the polymers protected with alkoxy-ethyl groups increased by $20 \sim 70^{\circ} \mathrm{C}$ compared with that of the THP group protected polymer. The polymers protected with alkoxy-ethyl groups also have higher thermal decomposition points than that of the THP group protected polymer. This is because the former have a strain-free structure and are thermally stable, while the latter have a cyclic structure and is less stable. THP group protected polymer is not so stable for the strain from the cyclic structure. The order of thermal stability was AEE $>$ MEE $>$ ETE. The decomposition temperature of the three polymers becomes higher as the chemical sift value of carbon in the acetal groups in ${ }^{13} \mathrm{C}-\mathrm{NMR}$ spectra increases (Table 2). This means that low carbon electric density results in high thermal stability. This low electron density of the carbon was induced by an electron-withdrawing of the substituent group. Therefore, introducing an electron-withdrawing group into alkoxy-ethyl groups contributes to enhanced thermal stability.

An alternative approach to increasing thermal stability is to introduce an alicyclic group. The thermal decomposition point of polymers protected by alkoxy-ethyl groups with an adamantyl group was around $200^{\circ} \mathrm{C}$, which was the highest decomposition point among the polymers. This indicates that introducing a substituent group like an adamantyl group into alkoxy-ethyl groups is a very effective way to improve thermal stability.

The FT-IR difference spectra (after baking-before baking) of ETE- and THP-group protected terpolymers are shown in Fig. 5. Here, the peak from the $\mathrm{COOH}$ group increases and that of the protecting group decreases, indicating that thermal decomposition is caused by the elimination of the protecting group. 


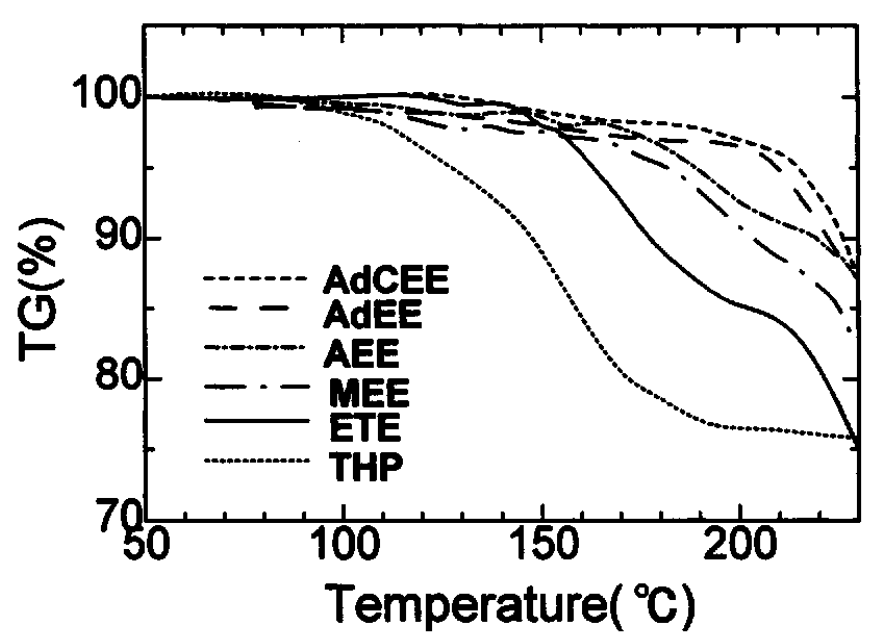

Figure 4 TGA thermogram of alkoxy-ethyl groups and THP group protected polymers. Heating rate was $10^{\circ} \mathrm{C} /$ minute.

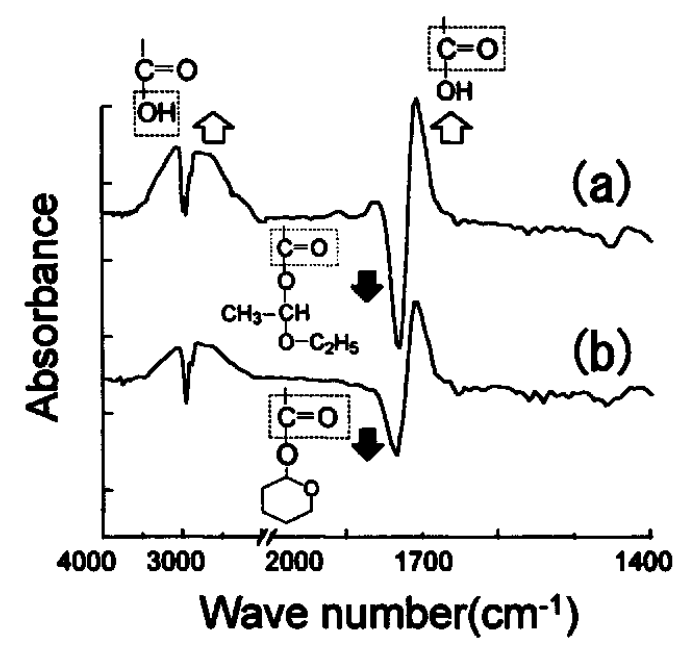

Figure 5. FT-IR difference spectra (after baking-before baking) (a)ETE group protected terpolymer (b)THP group protected terpolymer

Table 2. Thermal decomposition point of terpolymers and ${ }^{13} \mathrm{C}-\mathrm{NMR}$ chemical sift

\begin{tabular}{|c||c|c|c|c|c|c|}
\hline Protecting group & ETE & MEE & AEE & AdCEE & AdEE & THP \\
\hline $\left.\mathrm{T}_{\text {dec }}{ }^{1}{ }^{\circ}{ }^{\circ} \mathrm{C}\right)$ & 158 & 182 & 191 & 198 & 205 & 136 \\
\hline Chemical sift of $\mathrm{NMR}^{2)}$ & 96.72 & 97.10 & 97.35 & 96.78 & 97.40 & 92.83 \\
\hline
\end{tabular}
1) $5 \%$ weight loss
2)Chemical sift of ${ }^{13} \mathrm{C}-\mathrm{NMR}$ spectrum of carbon in acetal group

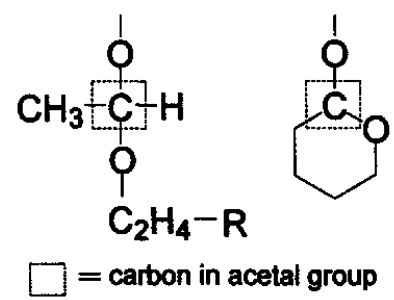

\subsection{Dissolution rate characteristics}

Dissolution rate characteristics are very important properties, because they determine the resist capability of the resist system. If the dissolution rate difference between the exposed and unexposed parts is sufficient and the slope of the dissolution rate curve is high, we can expect high resolution.

Figure 6 shows the dissolution rate characteristics of terpolymers protected with alkoxyethyl groups and the THP group as a function of exposure dose. The slopes of the dissolution rate curves in Fig. 6 are listed in Table 3. ETE, MEE and AEE group protected polymers had over three times the slope of THP protected polymers. On the other hand, the slopes of polymers protected with the AEE and AdCEE groups with the ester group were nearly equal to that of THP group protected polymer.

Figure 7 shows the dissolution rate characteristics of copolymers protected with the 
ETE group and THP group as a function of exposure dose. The slopes of the dissolution rate curves in Fig. 7 are listed in Table 3. The ETE group protected polymer had over four times the slop of the THP protected polymers, thus indicating that introducing the alkoxyethyl group into polymers improves the dissolution rate characteristics of terpolymers and copolymers.

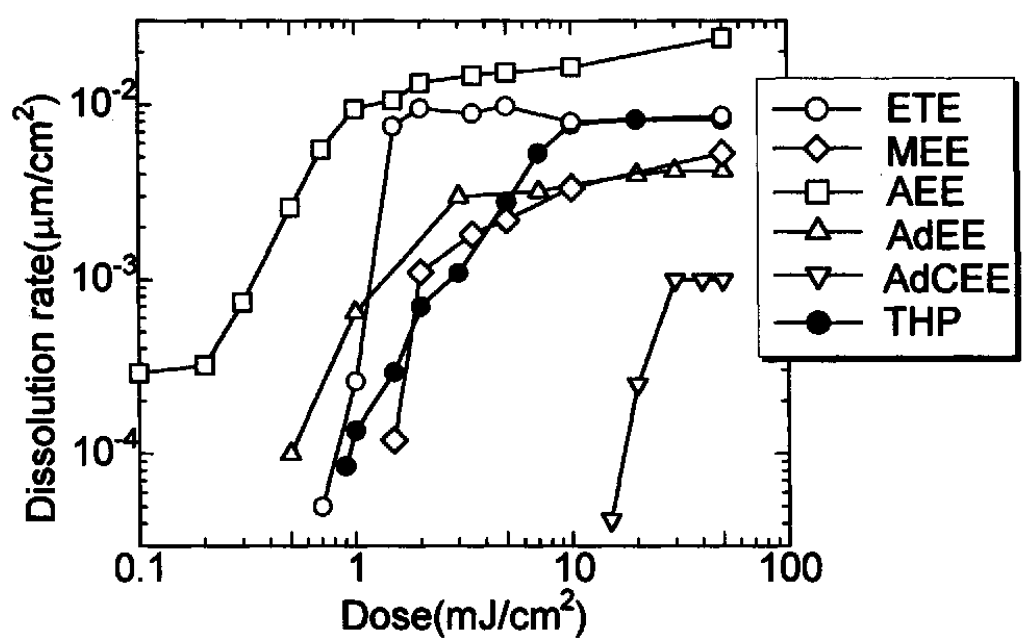

Figure 6. Dissolution rate characteristics of alkoxy-ethyl group protected terpolymers.

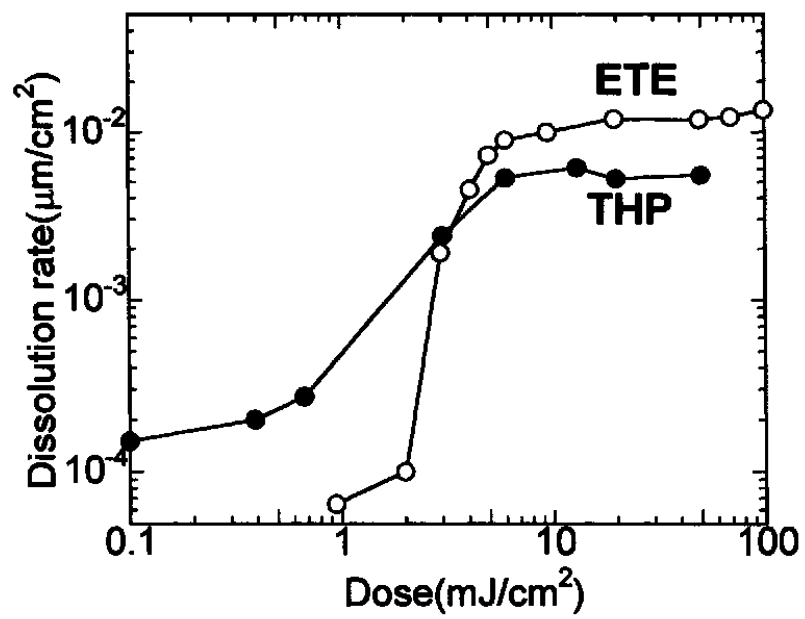

Figure 7. Dissolution rate characteristics of ETE group protected copolymer.

Table 3. Slope of dissolution rate curves

\begin{tabular}{|c||c|c|c|c|c|c||c|c|}
\hline \multicolumn{1}{|c||}{} & \multicolumn{5}{|c||}{ terpolymers 1$)$} & \multicolumn{2}{c|}{ copolymers 2$)$} \\
\hline Protecting group & ETE & MEE & AEE & AdEE & AdCEE & THP & ETE & THP \\
\hline Slope & 7.80 & 7.65 & 2.17 & 1.89 & 5.30 & 1.88 & 6.5 & 1.4 \\
\hline
\end{tabular}

1)PEB : ETE, AEE, MEE $60^{\circ} \mathrm{C} / 60 \mathrm{~S}$, THP $70^{\circ} \mathrm{C} / 60 \mathrm{~s}$, AdCEE, AdEE $100^{\circ} \mathrm{C} / 60 \mathrm{~s}$, PAG: TPS 2)PEB : $70^{\circ} \mathrm{C} / 60 \mathrm{~S}$, PAG: SIT 
Dissolution rate characteristics of alkoxy-ethyl protected polymers depend on the protecting group structures. We considered that these dissolution behaviors relate to the polarity and volume of the protecting groups. Figure 8 shows the relationship between relative dielectric constant and dissolution rate of unexposed terpolymers for $2.38 \mathrm{wt} \%$ TMAH solution. Here, dielectric constants are predicted from similar materials listed in the literature. $^{13}$ In general, organic compounds with larger polarity have larger electric constants. As shown in Fig.8, dissolution rate was proportional to the relative dielectric constant. This indicates that protecting groups with low polarity have a larger inhibition effect.

Figure 9 shows the relationship between the volume of the protection groups and the dissolution rate of a completely decomposed terpolymer after post-exposure baking(dose $50 \mathrm{~mJ} / \mathrm{cm}^{2}$ ). It indicates that a large protecting group, which produces a large decomposition product, has a higher inhibition effect. The dissolution rates of the polymers protected by the alkoxy-ethyl group with an ester group were higher than those of the polymers protected by the alkoxy-ethyl group without an ester group. These results indicated that the presence of weak polarity from the ester group promotes a dissolution reaction of the polymer. We thus demonstrated that the dissolution rate of the protected polymer can be characterized by the polarity and volume of the protecting groups.

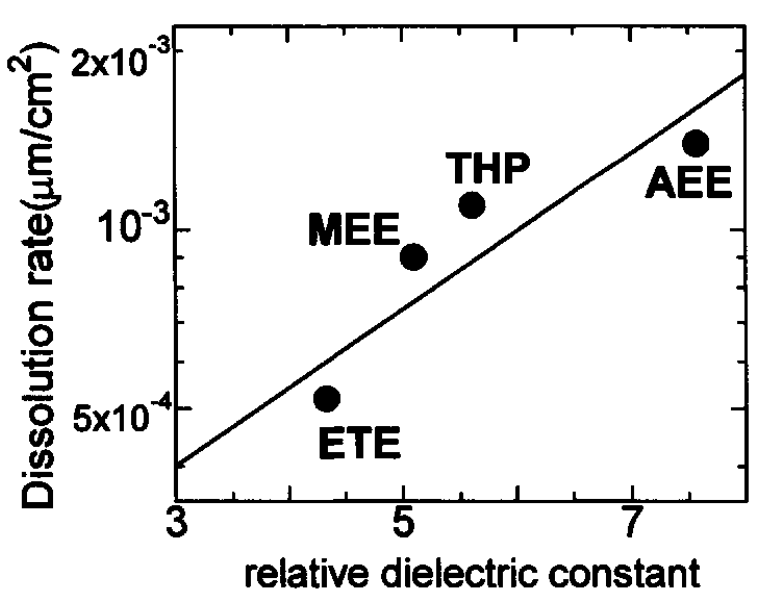

Figure 8. Relationship between relative dielectric constant and dissolution rate of unexposed terpolymers for $2.38 \mathrm{wt} \%$ TMAH solution.

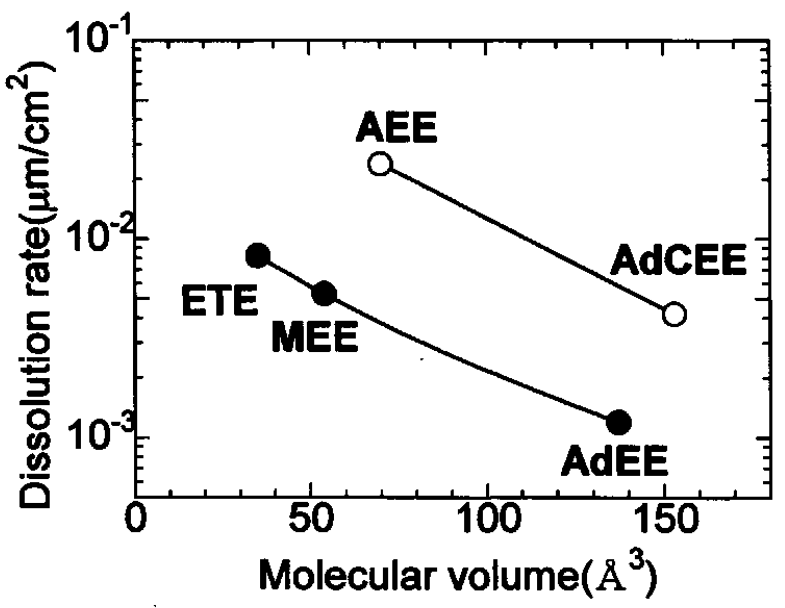

Figure 9. Relationship between molecular volume of decomposed product of protecting group and dissolution rate of exposed terpolymers for $0.048 \mathrm{wt} \%$ TMAH solution.

\subsection{Lithography performance}

Next, we describe a patterning experiment using an ArF contact printing tool. Resist sensitivities obtained in the experiment are listed in Table 4. As the table shows, most alkoxy-ethyl groups have a higher sensitivity than that of the THP group even at lower 
temperatures in post-exposure baking. This indicates that the alkoxy-ethyl group has higher acid decomposition efficiency than the THP group, which is known as the high acid decomposition group. This is because the developed protecting groups have a lower steric hindrance than the THP group.

Figure 10 shows the resist pattern profile of the ETE group protected copolymer resist using an ArF contact printing tool. As the figure shows, small pattern profiles of down to $0.15 \mu \mathrm{m}$ can be obtained through the use of the tool. The ETE group protected resists were found to have good resolution capability, as was expected from their good dissolution rate characteristics. Therefore, the indication is that introducing alkoxy-ethyl groups contributes to improved sensitivity and resolution.

Table 4. Sensitivity

\begin{tabular}{|c||c|c|c|c|c|c||c|c|}
\hline \multicolumn{1}{|c||}{} & \multicolumn{5}{|c||}{ terpolymers 1 copolymers } \\
\hline Protecting group & ETE & MEE & AEE & AdEE & AdCEE & THP & ETE & THP \\
\hline sensitivity $\left(\mathrm{mJ}^{\prime} \mathrm{cm}^{2}\right)$ & 1.0 & 1.4 & 0.4 & 10.0 & 4.0 & 7.5 & 6.8 & 8.2 \\
\hline
\end{tabular}

1)PEB : ETE, AEE, MEE $60^{\circ} \mathrm{C} / 60 \mathrm{~S}$, THP $70^{\circ} \mathrm{C} / 60 \mathrm{~s}$, AdCEE, AdEE $100^{\circ} \mathrm{C} / 60 \mathrm{~s}$, PAG: TPS

2)PEB : $70^{\circ} \mathrm{C} / 60 \mathrm{~S}$, PAG: STT

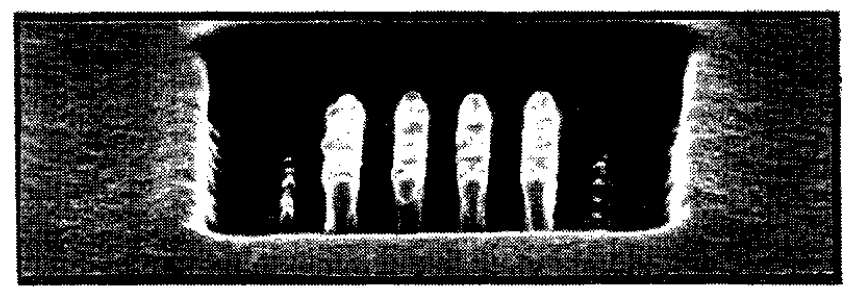

Figure 10. SEM micrograph of $0.15 \mu \mathrm{mL} / \mathrm{S}$ pattern.

Poly (TCDMACOOETE 40 -TCDMACOOH 60 ) /SIT(1wt\%)

resist exposed using ArF contact printing tool.

\subsection{Basic characteristics of alkoxy-ethyl groups}

Basic characteristics of alkoxy-ethyl groups protected polymers and resists are summarized in Table 6.

Table 6 Properties of alkoxy-ethyl groups

\begin{tabular}{|c|c|c|c|c|c||c|}
\hline & ETE & MEE & AEE & AdEE & AdCEE & THP \\
\hline Thermal stability $\left({ }^{\circ} \mathrm{C}\right)$ & 158 & 182 & 191 & 198 & 205 & 136 \\
\hline $\begin{array}{c}\text { Dissolution rate characteristics } \\
\text { (Slope) }\end{array}$ & 7.80 & 7.65 & 2.17 & 5.30 & 1.89 & 1.88 \\
\hline Sensitivity $\left(\mathrm{mJ} / \mathrm{cm}^{2}\right)$ & 1.0 & 1.4 & 0.4 & 10 & 4.0 & 7.5 \\
\hline
\end{tabular}




\section{Conclusion}

We have developed new alkoxy-ethyl protecting groups for ArF chemically amplified positive resist. The developed protecting groups showed excellent performances in thermal stability, deprotection reaction efficiency, and dissolution contrast. We found that the dissolution rate of the polymer protected with these groups was characterized by the polarity and molecular volume of the protection groups. We also confirmed that the chemically amplified resists with these protecting groups have good resolution capabilities. Our results lead us to conclude that new alkoxy-ethyl protecting groups are very suitable for use have excellent performances as protecting groups for $\mathrm{ArF}$ chemically amplified resists.

\section{Acknowledgments}

The authors would like to thank Y. Ogura and J. Yano at Optoelectronics Laboratories of NEC Corporation for their help with the ArF exposure.

\section{References}

1. K. Nakano, K. Maeda, S. Iwasa, J. Yano, Y. Ogura, and E. Hasegawa, "Transparent Photoacid Generator (ALS) for ArF Excimer Laser Lithography and Chemically Amplified Resist", Proc. SPIE, 2195, 194 (1994).

2. K. Nakano, K. Maeda, S. Iwasa, T. Ohfuji, and E. Hasegawa, "Positive Chemically Amplified Resist for ArF Excimer Laser lithography Composed a Novel Transparent Photoacid Generator and an Alicyclic Terpolymer", Proc. SPIE, 2438, 433 (1995).

3. K. Maeda, K. Nakano, T. Ohfuji and E. Hasegawa, "Novel Alkaline-Soluble Alicyclic Polymer Poly(TCDMACOOH) for ArF Chemically Amplified Resists", Proc. SPIE, 2724, in press (1996).

4. S. Takechi, Y. Kaimoto, K Nozaki, and N. Abe, "Alicyclic Polymer for ArF and $\mathrm{KrF}$ Excimer Resist Based on Chemical Amplification", J. Photopolym. Sci. Technol., 5, 439 (1992).

5. M. Takahashi, S. Takechi, Y. Kaimoto, I. Hanyu, N. Abe, and K Nozaki, "Evaluation chemically amplified resist based on adamantyl methacrylate for $193 \mathrm{~nm}$ lithography", Proc. SPIE, 2438, 422 (1995).

6. R. D. Allen, G. M. Wallraff, R. A. DiPietro, D. C. Hofer, and R. R. Kunz, "193 nm Single Layer Positive Resists Building Etch Resistance Into a High Resolution Imaging System", Proc. SPIE, 2438, 474 (1995).

7. R. D. Allen, I. Y. Wan, G. M. Wallraff, R. A. DiPietro, D. C. Hofer, and R. R. Kunz, "Resolution and Etch Resistance of Family of $193 \mathrm{~nm}$ Positive Resists", J. Photopolym. Sci. Technol., 8, 623 (1995).

8. T. Sakamizu, H. Shiraishi, H. Yamaguchi, T. Ueno, and N. Hayashi, "Acid-Catalyzed 
reaction of Tetrahydropyrany-Protected Polyvinylphenol in a Novolak-Resin-Based Positive Resist", Jpn. J. Appl. Phys., 31, 428(1992).

9. T. Hattori, L. Schegel, A. Imai, N. Hayashi, and T. Ueno, "Chemical Amplified Positive Deep UV Resist Using Partially Tetrahydropyrany-Protected Polyvinylphenol”, Proc. SPIE, 1925, 146 (1992).

10. H.Gokan, S.Esho, and Y.Onishi, "Dry etch resistance of organic materials", $J$. Electronchem. Soc., 130, 143(1983).

11. T. M. Chapman, E. A. Freedman, Synthesis, 591 (1971).

12. T. Ohfuji, K. Maeda, K. Nakano, and E. Hasegawa, "Dissolution behavior of alicyclic polymers designed for ArF excimer laser lithography", Proc. SPIE, 2724, in press (1996).

13. J. A. Riddick, W. B. Bunger, and T. K. Sakano, "Organic Solvents", John Willy \& Sons(1986). 